\title{
Learning Through Caring in the Clinical Settings
}

\author{
Jesson V. Butcon \\ Far Eastern University - Institute of Nursing, Philippines
}

\begin{abstract}
The study aimed to examine and explain the dimensions of clinical teaching gathered from the experiences of Centers of Excellence in Nursing Education (COE). The research endeavored to develop a theory of clinical teaching based on the best practices of four (4) outstanding schools offering a nursing program in the country.

Using multiple case study approach, a qualitative inquiry was conducted among four (4) COE schools triangulating data from key informant interviews, document review and actual observations. The findings of the study illustrated the unique features in clinical teaching practices from the four cases along dimensions of curriculum, instructional delivery, learning experiences, monitoring and evaluation of competencies, teachers' characteristics, learners' attributes and the learning environment. Data from these cases were analyzed using pattern-matching logic that revealed several propositions which served to form the emergent theory of clinical teaching, LEARNING THROUGH CARING IN THE CLINICAL SETTING

Implications such as grounding the theory in broader context, exploring the dimensions in relation to competency development and using the theory in practice and research to eventually influence the policy environment of nursing practice were recommended based on the findings of the study.
\end{abstract}

\section{Introduction}

The clinical component in the nursing curriculum has been reputed to inadequately prepare students for professional nursing (Udlis [28]). While the current structure provides for a Related Learning Experience (RLE), a clinical practicum designed to actualize learned competencies through clinical teaching, the current practice is beset with overwhelming problems linked with the issue of inadequacy of the current clinical teaching pedagogy.

In most instances, clinical teaching occurs in the context of a fast-paced and dynamic environment, with practitioner-teachers struggling to handle the dual roles of patient care provider and teacher. This is because the clinical environment is characterized by multiple tensions caused by patient caseloads, unpredictable pace of on-going treatments, and multiple and conflicting responsibilities making clinical teaching compete with patient care concerns (Irby and Bowen 2004 as cited by Dolmasn et al., [9]). These complexities pose a challenge to clinical teachers to devise an approach in teaching RLE that will promote high-quality learning environment and meaningful practice.

Available literature offers general teaching frameworks for classroom and clinical teaching but fails to consider the dimensions encompassing the nature and context of RLE in the Philippine BSN curriculum. Moreover, while half of the BSN curriculum (around 2,500 hours) is allotted for RLE, anecdotal reports reveal that the implementation of course delivery is inadequately conducted due to lack of competent clinical teachers and poor choice or even absence of appropriate pedagogy. To a large extent, classroom pedagogy is applied in the clinical scenario ignoring the difference in context and pedagogical demands between the two settings. This happens because of the dearth of clinical teaching models developed for Philippine nursing schools.

Thus, this study attempted to evolve a theory of clinical teaching that does not merely adopt the classroom model. By so doing, the study hopes to contribute to the existing literature by developing an initial theory proposition on clinical teaching that balances the features and constraints in the implementation of RLE. The choice of COE schools was made on the assumption that their practices approximate the ideal arrangements of RLE in nursing schools.

\section{Method}

A multiple case study design was used to explore and analyze the features of clinical teaching in COE schools. Data sources were in-depth interviews, observations and documents review to discover the best features and practices in clinical teaching among the four schools. Participants of the interviews were deans, academic administrators, senior and junior teaching staff, and students who were interviewed separately at an average of 90 minutes per contact using an interview guide. Meanwhile, a document 
review form was utilized to gather data on curriculum design, evaluation tools, and learning diaries if available. Lastly, the research employed field observation to document actual interactions observed between the clinical preceptors and the students.

Analysis employed pattern matching; a kind of analysis that matches the actual from the expected as well as a synthetic and reflective strategy to combine the actual data, literature and personal accounts from the researcher's observation and experience. To contextualize the analysis of the gathered data, "within case" and cross-case" analyses were undertaken taking note of specific pattern-match and existence of a rival theory. The convergence of evidence was aimed at arriving at acceptable facts that are expected to result into a structured and coherent theory. The core categories were explained using the triangulated data from actual sources, reviewed literature and researcher's inferences and conceptual abstractions from the actual observations and interviews. The process resulted in the development of a model for clinical teaching.

\section{Results and Discussion}

The cases demonstrated several unique practices in clinical teaching revealed through the examination of the dimensions of curriculum and instruction, monitoring and evaluation, the learning environment, the characteristics of the teachers, and the attributes of the learners.

\subsection{Curriculum Design and Delivery}

Curriculum design and delivery system are two integral components in clinical teaching. Wellcrafted designs clearly communicate the expected outcomes across various learning experiences that are the core competencies for the practice of the nursing profession. These core competencies are developed through meaningful learning experiences that are carefully planned.

The bulk of the educational experience of nursing students occurs in the clinical areas as reflected in the curriculum of the four schools. More than half of the 4-year program is devoted to learning professional roles through actual interaction guided by the clinical teachers.

In the four cases examined, goals were articulated based on the mission-vision, and school philosophy of the particular school that served as the bases for determining the differentiated contents and modes of delivery. All the deans related the care they have exercised in setting and clarifying the goals and objectives to all the important stakeholders (i.e. students, clinical instructors, and other members of the staff). They emphasized the importance of having clear learning goals in clinical teaching.
For their part, the other sectors also indicated that the goals and objectives and the other components of the curriculum are clear to them. This is in consonance with Little's (2007) assertion that the strong connection among goals, content, and pedagogy communicates a clear message to the users on what expectations are at hand. Given the complexity of the clinical situations and the changes in the characteristics of the learners, Carter (2008) recommended that setting and clarifying the goals of learning are essential in building a strong connection between teaching and learning that enhances the effectiveness of the process.

With clear learning goals, standards and expectations are set, and instructions become clearer and easier to follow. Instruction not only causes compliance but is also expected to result in greater autonomy and self-direction among the learners (Harvard, 2008). The document review reveals that the focus of teaching is on the acquisition of decision-making skills. This focus finds support from Imig (2008) who argues that since nursing education takes place in clinical situations where life is at stake, the acquisition of decision-making skills that require accuracy and precision must be emphasized at the beginning of the encounter.

Meanwhile, essential to teaching in clinical scenario is the close-match between learning needs and instruction, a concept that became evident in the four nursing institutions during the cross-cases analyses. All the deans agree that determining the learners' need is important to make instruction compatible with actual needs of the learner. However, they argued that this task is easier to accomplish in the classroom than in clinical areas where there are concerns like unfamiliarity with the environment and learners' anxiety. They indicated that they continuously look for creative ways in the diagnosis of learning needs rather than on merely relying on test results, a type of practice that according to Paoletti [25] oftentimes do not correlate with what the learners can actually perform.

The assessment of needs is essential for planning and implementing more effective instruction. Effective course delivery assumes that there is an ongoing assessment of needs as these are usually dynamic and changes as the learning activities unfold. Reilly [24] explains that needs assessment requires teachers in the clinical area to listen carefully to learners by tuning in to their learning progress and styles. In this way, effective clinical teachers are then able to interpret these needs and delineate learning problems as either "pathological" - those that needs immediate attention and "developmental" - those that can be classified as under watchful waiting.

Furthermore, Reilly emphasized the need for appropriate leadership in teaching medical students in the clinical area as an essential dimension. Among 
the styles, the democratic style provided better outcomes. Teaching democratically is all about activating learners' initiative, thus providing them with self-assessment tools that not only promote independence but also develop a sense of accountability to their own learning.

Based on the triangulated data from the four cases, clinical teaching as designed and prescribed in their respective curricula emphasizes reinforcement of learned concepts and skills and is used to enhance competencies. The design of their RLE enables the teacher to create more meaningful experiences that allow the students to practice their competencies until mastery. Whether done experientially (actual or simulated) or virtually, this important component of RLE provides opportunities for students to play the role of a professional nurse throughout their course of study.

Contextualized teaching (case-based, need-based or problem-based) according to teacher informants using actual cases attended by students in the clinical areas is the most common approach used to teach competencies for professional training. Oftentimes, the case analysis makes use of technology. The effectiveness of these strategies has long been supported by empirical evidences. For instance, Lonnes found out higher significant competencies among those who were trained using non-traditional methods of instruction. Moreover, innovativeness of teachers in clinical situations using technologymediated approaches strengthens the intrinsic motivations of learners as their cognitive absorption increases with technology use (Tan [27]). Because of this approach, the student nurses in this study became more confident in dealing with their actual tasks with real patients in the clinical setting as predicted by current empirical literature.

To insure effective delivery, the four nursing institutions adequately invest in retooling their faculty as revealed by the four deans and confirmed by various documents surveyed. This is important because, while most of these teachers doing clinical teaching are content experts, they are not necessarily equipped with the skills that will enable them to facilitate meaningful education. The use of appropriate pedagogy is a science, hence Corcino [7] suggests that it is imperative for schools to invest in re-tooling their faculty on the application of basic pedagogical interventions considering that most of those involved in clinical teaching lack experience and theoretical background on teaching.

The four institutions also provide close monitoring and supervision of instruction as well as the progress of learners. A well-defined guideline for monitoring and supervision with well-defined roles and functions are well documented. This not only ensures that the curriculum is properly implemented but also that those who need assistance and guidance can avail of them. This is an important quality assurance measure that creates a culture of continuous improvement to attain excellence.

According to Schonwetter et al. [26], the close physical proximity of instructor to students coupled with continuing communication and higher dynamics of rapport add up to the effectiveness of instruction. Because the clinical settings are complex and intimidating to young learners, close accompaniment of students is a caring gesture that not only could allay anxiety but also improve learning and increase retention. The role of pedagogy in clinical teaching is essentially important especially because RLE is a learning situation where the learning condition is constrained by environmental limitations (i.e. hospital policy, mix of cases, volume of students).

The reports of the teacher and student informants reveal a healthy and "helping and caring relationship" that characterizes the kind of monitoring and supervision of learning that exists in the four cases. This concept of supervision has also evolved over the years as more empirical literature suggests proactive approaches to address learning needs. The factor of intimidation from the "preceptorial relationships" in medical and allied health science education in the past is now replaced with the concept of "gentle interruptions" (McAllister [20]), where teachers serve as caring coaches who offer supportive instructions to novice practitioners. This is in consonance with Reilly's [24] assertion about the role of clinical teachers as "interventionist"- who provides the student supplemental learning to enrich experience with an expert view and evidence-based findings demonstrating a caring behavior.

Analysis of interviews of the four cases reveals the use of variety of techniques in the delivery of instruction to improve learning. In all four cases, the students are given the opportunity to observe and practice the learning skill based on the principle of “ learning by doing” which Kim and Lyons [15] emphasized is a very effective strategy. According to them this is the favored mode of delivery of creative and innovative teachers. Unfortunately in some institutions, due to volume of students, lack of cases, competition with other health professionals, lack of logistical requirements, and poor coordination between educational and health institutions, opportunities for students to practice their skills are diminished (Decker [8]) resulting to poor performance when they practice nursing or pursue other work after graduation in some institutions. However, this is not the case in the four institutions under the investigation, rather the application of the principle is a "best practice" for them.

For his part, Orphanos emphasized the importance of also providing parallel opportunity for practice because nursing students are not only trained to make decisions but perform those decisions as 
action/response to patients' problems. To him if opportunity for practice were scarce, then learning would be constrained. The various informants of this study also confirm adherence to this principle by allowing their students to go through learning experiences using virtual and simulated cases before dealing with real patients.

Aside from provision of opportunity for practice, students in the four cases are also encouraged and required to reflect on their experiences. Two of the cases require their students to write their reflection in writing in a learning diary and portfolio (case 1 and 3 ). The other two require their students to verbalize their reflection orally. Irby and Bowen (2004) as cited by Dolmans et al [9] argue that encouraging students to reflect can have positive effect on learning especially when these reflections are connected to the expected professional roles of the students. Reilly [24] emphasizes that in clinical teaching, it is always necessary to expose students to the ambiguity and ambivalence inherent to clinical practice so that with guided reflections, they can develop and sharpen their problem-solving skills and at the same time, imbibe values such as honesty and humility.

Finally, 3 out of the 4 cases put significant emphasis on cooperative learning and collaborative teaching. According to the 4 types of informants, they all recognize the pivotal role of learners in the learning process. In cooperative learning, learners are encouraged to work with their peers as they discover facts and develop skills while supporting each other. Collaborative teaching emphasizes two things: 1) recognition that adults want to collaborate and be self-directed and, 2) need for specialty teaching (Beckman and Lee [1]). Based on empirical studies, both cooperative learning and collaborative teaching are effective in teaching clinical and decision-making skills in patient care. Thus, involving learners and the entire health care team in learning is most effective especially when designed purposely to address specific needs.

Across cases, the conceptual meaning of the themes "having clear learning goals", "caring modes of delivery of instructions", "contextualized teaching”, "close supervision of learning”, "having opportunities to observe and practice the skills", providing venues for reflective learning”, “ using gentle interruptions" and "use of collaborative/cooperative teaching" yielded the following first proposition for the study.

\section{Proposition No. 1}

To prepare the learners to the professional roles of the nurse, teacher models professional behavior(s) and student actualizes the role (s) guided by carefully designed learning goals through creative caring modes of delivery that promote competency, empowerment, confidence, reflection and collaboration.

\subsection{Monitoring and Evaluation in Clinical Teaching}

Providing learning feedback is important in the learning process. When given timely and appropriately, it is expected to correct skills gap while at the same time increase motivation of learners (Menix [23]). Giving of feedback is essential in clinical teaching especially when dealing with adult learners as explained by faculty informants from the four cases. Unique to the experience of the subjects in the study is the use of a variety of creative feedback mechanisms including reflections as seen in cases 1 and 3. This observation is supported by Allen's study in 2005 wherein the combined cognitive and profile awareness plus metacognitive instruction did not only yield good learning outcomes, but also better qualitative observations of the learners. Likewise, this bolsters the previous claim of Menix's on the effect of skills gap and motivation of students towards learning that can be changed with feedback and guided reflections.

According to the faculty informants, the evaluation of the process and the resultant decision provide more important insights than the outcome itself especially when done creatively and holistically. Evaluation activities as practiced by the cases endeavored to create more reflections as it encompass not just tangible results but also the intangible outcomes of the program i.e. emphasis on values and partnership with parents (case 3), focus on reflections (case 1) and integration of biblical teachings (case2).

Similar to the findings of Menix, monitoring and evaluation of learning outcome in the four schools are considered integral and critical components of the learning process which is an important step to determine the worth, effectiveness and success of the curriculum design. Across the four cases, the strong practice of linking monitoring and evaluation to instructional goals were noted as best practice

But more than doing monitoring and evaluation of outcome, the four institutions view monitoring and evaluation activities, similar to Lazaruk[16], not only as checking of results but as bases to progressive learning with the participation of the students, this is because adults generally like to involve themselves in the learning process. Students and faculty informants of case 4 even reveal the use of self-assessment measures, which they acknowledge definitely help them improve performance and enhances skills. In fact, most of these cases use authentic evaluation in addition to the traditional mode, as students are assessed as they actually perform the task using valid and reliable criteria. This practice is in contrast to what Paoletti' 
[25] cautioned on using assessment merely for grading and placement decisions rather than for planning and implementing more effective instructions.

The value of collaboration in monitoring and evaluation is already an established phenomenon. For cases 3 and 4, the stakeholders collaborate not only in the design implementation but also in the evaluation of the program. The effort of ensuring that multiple perspectives are examined does not only bring forth cooperation, but initiates the negotiation process in learning. Based on Reilly's observation, while the clinical teacher typically leads teams of learners with different skills level, the "group tango" can be improved by collaborating with the rest of the team and enabling learners to negotiate in terms of expectations of performance and learning, therefore, making them more engaged and involved in the teaching-learning process.

According to Melrose [22] as echoed by the faculty informants in the study, providing observations and feedback to learners allows them more opportunities to grow and enjoy the learning process while responding independently or with assistance to the deficiency in the required competencies. Creating a caring learning environment that sets and communicates high expectations and standards of learning not only encourages superior performance but also rewards learners as they begin to acquire expertise in the roles that they play especially when the caring learning climate is sustained. This finding supports the argument of (Beckman and Lee [1]).

The overall picture of successful nursing programs as revealed in the practices of the four (4) resulted in proposition no. 2. This proposition was crystallized from the conceptual themes i.e. "endeavoring reflections through participatory monitoring and evaluation", "use of authentic evaluation measures", "giving timely and progressive feedbacks", and "focused and individualized evaluation”.

\section{Proposition No. 2}

A variety of creative, well-designed collaborative, constant and caring competency monitoring and evaluation not only encourages superior performance of students but also improves the teaching-learning process.

\subsection{Monitoring and Evaluation in Clinical Teaching}

The challenges nurse educators encounter and respond to while teaching in the clinical area require a unique set of skills and teaching expertise different from those acquired through classroom teaching. The faculty respondents indicated as much during the interviews. This is because, according to them, of the very unpredictable clinical situations that requires higher adaptability and precision.

For their part, the deans assert that clinical teaching requires teachers to possess knowledge of the discipline, planning and organization, delivery skills including communication and evaluation, rapport with the student, administrative skills and more importantly caring skills. Furthermore, more than experience and competence, having relevant trainings in a specific area of specialization is needed in order to effectively influence skills development and satisfaction. These requirements agree with Chen's [6] assertion that specialized teachers are sufficiently equipped with content and pedagogy enabling them to easily convey instructions effectively even under stressful clinical situations.

On the other hand, Paton emphasizes that along with experience, competence, and relevant trainings, a heightened service orientation is an important attribute of a clinical teacher. The present study revealed that the faculty especially of case 1 and case 3 view their work as a vocation or service. Because of this orientation they value their students and become more sensitive to their needs and more caring which enhance learning. This is similar to the findings of Egan [10] who found out that because clinical teaching employs simulations and modeling, successful teachers are those with positive view of their work either as a vocation or service.

To insure satisfaction of learners, specific traits and personality requirements are necessary for effective clinical teaching. The present study revealed similar findings to the assertion of Calderhead [3] and Kawell [14] that successful teaching requires exceptional relatedness with learners and a type of personality that can be described as strict, but fun and caring as very evident in case 1 and case 3 . In addition to relational skills as an essential requisite to connect with the learners, the teacher must be viewed as coach or mentor.

Another common best practice across the four cases, is the ability, as what Reily claims, to diffuse skills and simplify complex tasks. In all four cases, the deans emphasized that their clinical teachers are capable of teaching in concise and clear expressions of thoughts. According to student informants, their clinical teachers recognize the difference between scientific knowledge (those with intrinsic value) and clinical knowledge (those that has value to patient care). This finding supports Reilly's explanation that the task of the teacher is to translate complex clinical knowledge about the cases and make logical and sound decisions about them.

Reilly emphasizes that more than pedagogical concerns, it is the leadership of the teacher that inspires and even motivates students to achieve their performance potentials as they struggle through the fits and starts, blind alleys, and missteps in clinical practice. The deans stated that their clinical teachers 
as a rule guide the students when they struggle through very difficult and complex situations. Their teachers model problem-solving in the clinical scenario. Because of this practice, the students perform better as their teachers shift roles from supervisors of performance to skills coach, providing not only theoretical instruction but also comforting support.

Lastly, while commitment to teaching and dedication to the nursing profession were strong values identified by student informants, more importantly, their experience with their teachers facilitated the understanding of the real meaning of work, including undergoing humbling experiences of making mistakes and making wrong decisions (especially those from case1, case 2 and case 3). This is a practice that Matzorou [19] adds can be a powerful tool that facilitates reflection and enhances critical thinking among learners.

The clinical teaching demands that evolved from the themes "specialized teaching", "vocation or service-orientation" and "commitment to teaching and dedication to the profession through honest practice” resulted in proposition 3 .

\section{Proposition No. 3}

Effective teachers journey with their students and model not only the skills and caring required for successful professional practice but also the values and attitudes needed for a profession that requires a very strong service orientation.

\subsection{Monitoring and Evaluation in Clinical Teaching}

The ultimate measure of the effectiveness of any academic program is demonstrated by the quality of its graduates. The COE schools selected for the study are established institutions of higher learning with very selective admission, stringent retention policies, and high completion rate. These schools are able to be selective because of the good reputation and image in the community that enable them to attract a large number of applicants every year. The high completion rates are attributable to the fact that these schools primarily admit students with superior learning traits.

But more than intelligence or talents that are revealed by aptitude tests students undergo as part of the screening process, these schools require students to possess the traits compatible with the demands of the profession that are actually reckoned with during their period of training. Yates [30] concludes that inclinations to specific professional practice as measured in aptitude tests have direct linear relationship with overall success later in the program or in their career. However, he cautions that these are not the only factors to consider: motivations and interests are critical elements too for success.

According to the faculty informants, the motivations and interests of the learner are developed overtime while undergoing the teaching-learning process. In other words, their experiences while undergoing training for the profession increase and deepen their motivations and interests to pursue and commit to become nurses. This confirms Groen's [11] point that one's life experiences could be influenced and clarified with the use of specific pedagogy of instruction that would foster reflection and appreciation of future roles. Based on the accounts of several interviewers in this study, the RLE experiences serve as a venue for learners to fit in the professional roles of the nurse and not just as an opportunity to practice skills. They also provide a venue for reflection and discernment according to the four deans that increase their commitment to their future profession and the resolve to become competent nurses after graduation.

Learners that are adaptive to rigorous training and high expectations serve as stimulus to effective clinical teaching-learning as revealed by case 1 and 4. According to Chickering and Gamson (n.d.), communicating high expectations to students make them strive harder to meet expectations and eventually when they achieve their optimum performance, they serve as the motivation to the development of more appropriate strategies for clinical education. This points to the need for creating a caring environment of high expectations in the clinical setting.

Based on the reported practices and the themes of “qualities of learners', “aptitudes”, “interests and motivations" on the four COE schools as requisites for producing excellent graduates, proposition no. 4 for the study is developed.

Proposition No. 4

The learning through caring of properly screened students during their period of clinical training increases or deepens their motivation and interest to pursue and commit to their chosen profession and resolve to become competent professionals after graduation.

\subsection{Learning Environment in Clinical Teaching}

The erratic changes in the demand of the industry and national higher authorities in the nursing education of the country, serve as impetus for the periodic and regular review of the curriculum according to the deans and faculty, as a basis for not only enhancing but also insuring that the curriculum continues to respond to the changing times.

The challenge is clear for clinical teaching and points to the need to make the practice in nursing 
education relevant to the changing demographics and the worsening national and global health care situations. This concern was felt initially by the deans as the increasing mismatch of graduate competencies vis-à-vis actual needs of the industry became apparent and documented across the health care delivery system. To respond to the situation, the nursing educators decided to streamline the implementation of clinical teaching with focus on requiring more serious work to fit the practice with the current and future contexts of health care demands with the adequate support of top management.

Across the four cases, there were concerted efforts to establish a supportive learning environment characterized by: "positive organizational and learning culture", "clear standards and expectations learning" and "supportive policy environment harmonizing resources (human, material, financial) practices and standards" (a pattern revealed not only during the interviews but also by observations and document review). The findings clearly demonstrated the role that organizational support plays in terms of the success of the four institutions. It also validated the principle as synthesized from the reflections of Deans, faculty and student informants that when standards of learning reflect and conform to the academic and corporate goals and objectives of the school, clinical teaching can become the venue for meaningful and exciting learning that provide a contrast to tedious classroom and laboratory instruction.

Thus, it is clear from the findings of the study that an important concern in the learning environment is the quality of the learning environment that institutions of learning must commit their resources and energies (human, material and financial) as requisite of success. Beckman and Lee emphasizes that creating a supportive learning climate foster a culture that breeds collaboration, value for diversity, openness to change and adherence to agreed established norms and standards.

Strategic partnership with other sectors/agencies and autonomy in terms of teaching practices also created the environment that fosters creativity and optimum learning. This was highlighted by faculty and students informants in the interview (cases 1 and 4) and was validated in the implementing policies and guidelines of their program. These findings are in consonance with Beyerlein's (2008) explanation on creating hopeful learning environments that enable educators to do their work better which entails the removal of structural barriers and the creating of healthy relationships. As reflected by the Dean in case 3 which echoes Beyerlin's [2] statement: "it is in creating harmony in policies, practices and relationships towards a goal of building a community of learners that is more important about the learning environment to neutralize the complexity of today's technology-driven society."

Based on the investigation about the learning environment that yielded the themes "supportive learning environment”, "positive organizational and learning culture", "responding to the needs of the changing times" the following proposition no. 5 is developed for the study.

\section{Proposition No. 5}

Effective clinical learning takes place with adequate caring support (human, material financial) of the organization that remains faithful to its commitment to provide quality education even during periods of unpredictability and inconsistency by creatively responding to the needs of the times.

\subsection{The Theory of "Learning through Caring in the Clinical Setting"}

To prepare the learners to the professional roles of the nurse, teacher models behavior and student actualizes the role/s guided by established learning goals through creative and caring modes of delivery that promote competency, empowerment, confidence, reflection and collaboration in the clinical setting. A variety of creative, well-designed, collaborative, constant, and caring competency monitoring and evaluation not only encourages superior performance of the students but also improves the teaching-learning process. Effective clinical teachers journey with their students and model not only the skills and caring required for successful professional practice but also the values and attitudes needed for a profession that requires a very strong service orientation. The learning through caring of properly screened students during their period of clinical training increases or deepens their motivation and interest to pursue and commit to their chosen profession and strengthen their resolve to become competent professionals after graduation. Effective clinical learning takes place with adequate and caring support (human, material financial) of the organization that remains faithful to its commitment to provide quality education even during periods of unpredictability and inconsistency by creatively responding to the needs of the times.

\section{Implication of Findings, Conclusion and Recommendation}

In terms of theoretical contribution, this research has provided data-based understanding of clinical teaching as a specialized pedagogy. In nursing education, the theory has implication on the existing competency development framework of RLE. While the curriculum of nursing in the Philippines has shifted to competency-based designs, the 
implementation of the program still operates within the traditional context of instruction deemphasizing the attributes to effective learning in clinical setting. Hence, this theory could provide descriptive explanations of the areas of improvement in the design and implementation of the RLE.

Moreover, there is still not enough research on clinical teaching and it is still viewed entirely as "classroom teaching" brought to the clinical situations. The findings of this research and the resulting framework of clinical teaching could serve as the basis for future researches. The validation of the framework through the gathering of more scientific evidences could improve the theory formulation already accomplished at this point.

Finally, findings from the four cases investigated and the resulting theory provide information regarding possible education policy standards formulation. The findings may be utilized to revisit existing provisions in the law and its implementing guidelines or PSGs (Professional Standard Guideline) as bases for revising certain provisions that do not necessarily promote or may even constrain effective professional competency development of nurses.

Overall, the conclusion and recommendations set above are hoped to connect understanding among scholars, policy-makers, and practitioners concerning competency development and clinical teaching in nursing schools.

\section{References}

[1] Beckman, T.J and Lee, M.C. (2009). Proposal for a collaborative approach to clinical teaching. Special Article, Mayo Clinic.

[2] Beyerlein, R. (2008). Creating hopeful learning environments: Collisions in practice. Michigan State University. Proquest Online Dissertation retrieved on June 25, 2009.

[3] Calderhead, S.A. (2008). College students' perceptions of effective teaching personality traits: A quantitative analysis of traditional versus online education. Capella University. Proquest Online Dissertation retrieved on June 25, 2009.

[4] Carter, M. M., et al. (2006). Cultural competency training for third-year clerkship students: Effects of an interactive workshop on student attitudes. Journal of the National Medical Association. Washington: Nov 2006. Vol. 98, Iss. 11; pg. 1772, 7 pgs

[5] Carter, P.J. (2008). Defining teacher quality: An examination of the relationship between measures of teachers' instructional behaviors and measures of their students' academic progress. The University of North Carolina at Chapel Hill. Proquest Online Dissertation retrieved on June 25, 2009.
[6] Chen, J.W. (2008). A study of instructors' background insports and leisure and their teaching effectiveness in Taiwan. United States Sports Academy. Proquest Online Dissertation retrieved on June 25, 2009.

[7] Corcino-Marrero, L. (2008). Conceptions that guide the teaching of the concept of function by college professors. University of Puerto Rico. Proquest Online Dissertation retrieved on June 25, 2009.

[8] Decker, S., et al. (2008). The evolution of simulation and its contribution to competency. The Journal of Continuing Education in Nursing. Thorofare: Feb 2008. Vol. 39, Iss. 2; pg. 74, 7 pgs

[9] Dolmans, DHJM et al. (2008). Factors adversely affecting student learning in the clinical learning environment: A student perspective. Education for Health. Vol. 20, Issue 3, 2008.

[10] Egan, M.C. (2008). An investigation of successful mathematics teachers serving students from tradionally underserved demographic groups. Boston College. Proquest Online Dissertation retrieved on June 25, 2009.

[11] Groen, J. F. (2009). The impact of pedagogical practice on student interest in elementary science classrooms. Queen's University, Canada. Proquest Online Dissertation retrieved on June 25, 2009.

[12] Harvard, K.A. (2008). Changes in knowledge, attitude and behavior as a result of utilizing evidence-based medicine among medical residents. Tui University. Proquest Online Dissertation retrieved on June 25, 2009.

[13] Imig, A. (2008). A case study of teacher effectiveness in Advanced Placement courses. George Fox University. Proquest Online Dissertation retrieved on June 25, 2009.

[14] Kawell, S. E. (2009). Successful teachers: What it takes to raise academic achievement of urban minority students. The Claremont Graduate University. Proquest Online Dissertation retrieved on June 25, 2009.

[15] Kim, B.R., et al. (2003). Experiential activities and multicultural counseling competence training. Journal of Counseling and Development : JCD. Alexandria: Fall 2003. Vol. 81, Iss. 4; pg. 400

[16] Lazaruk, A. (2007). Planning to stay: A participatory evaluation process. University of Manitoba, Canada. Proquest Online Dissertation retrieved on June 25, 2009.

[17] Little, C.A., et al. (2007). A study of curriculum effectiveness in Social Studies.The Gifted Child Quarterly. Cincinnati: Summer 2007. Vol. 51, Iss. 3; pg. 272, 13 pgs.

[18] Luquis, R., et al. (2006). Cultural competence development in health education professional preparation programs. American Journal of Health Education. Reston: Jul/Aug 2006. Vol. 37, Iss. 4; pg. 233, 9 pgs

[19] Mantzorou, M. (ND). Preceptorship in nursing education: Is it a viable alternative method for clinical teaching. HTEI of Athens. 
[20] McAllister, M., et al. (2007). Gentle interruptions: Transformative approaches to clinical teaching. Journal of Nursing Education. Thorofare: Jul 2007. Vol. 46, Iss. 7; pg. 304, 9 pgs

[21] McGill, I and Beaty, L (1995). Action learning, second edition: a guide for professional, management and educational development. Kogan Page, London.

[22] Melrose, S. (2004). What works? A personal account of clinical teaching strategies in Nursing. Center for Nursing and Health Studies, Canada. Education for Health Vol. 17, No. 2, July 2004.

[23] Menix, K. D. (2007). Evaluation of learning and program effectiveness. The Journal of Continuing Education in Nursing. Thorofare: Sep/Oct 2007. Vol. 38, Iss. 5; pg. 201, 8 pgs

[24] Reilly, B. M. (2007). Inconvenient truths about effective clinical teaching. The Lancet. London: Aug 25Aug 31, 2007. Vol. 370, Iss. 9588; pg. 705, 7 pgs

[25] Paoletti, L.H. (2009). Exploring factors influencing teachers' use of student assessment data for making instructional decisions. Teachers College, Columbia University. Proquest Online Dissertation retrieved on June 25, 2009.

[26] Schonwetter, D.J et al. (2006). Students' perception of effective classroom and clinical teaching in dental and dental hygiene education. Journal of Dental Education. Vol 70, Numer 6.

[27] Tan, W. (2008). An integrated view of cognitive absorption in technology-mediated learning environment. Concordia University. Canada.

[28] Udlis, K. A. (2008). Preceptorship in undergraduate nursing education: An Integrative Review. Journal of Nursing Education. Thorofare: Jan 2008. Vol. 47, Iss. 1; pg. 20, 10 pgs.

[29] Vajoczki, S. (2008). Effective teaching and teaching evaluation practices: Canadian university geography departments. Wilfrid Laurier University, Canada. Proquest Online Dissertation retrieved on June 25, 2009.

[30] Yates, L. (2007). The relationship of aptitude, course grades, and program length, to performance on a standards based test (NCLEX-RN). Published Dissertation by the Florida International University. 